\title{
Arte e política no Recife pré-1964: o Teatro Popular do Nordeste de Hermilo Borba Filho e de Ariano Suassuna ${ }^{1}$
}

\author{
Luís Augusto da Veiga Pessoa Reis ${ }^{2}$
}

Resumo: Este artigo propõe uma breve reflexão sobre as relações entre a arte e a política, enfocando um momento particularmente tenso e instigante na história do teatro em Pernambuco: a montagem da peça A bomba da paz, escrita e dirigida por Hermilo Borba Filho, em 1962, pelo Teatro Popular do Nordeste (TPN), grupo idealizado pelo próprio Hermilo, em parceria com o dramaturgo Ariano Suassuna. Palavras-chave: Hermilo Borba Filho. Ariano Suassuna. Teatro pernambucano. Ideologia.

Abstract: This article proposes a brief reflection on the relations between art and politics, focusing on a particularly tense and thought-provoking moment in the history of theatre in Pernambuco: the staging of the play A bomba da paz, written and directed by Hermilo Borba Filho, in 1962, produced by the Teatro Popular do Nordeste (TPN), a theatre group conceived by Hermilo himself, in partnership with the playwright Ariano Suassuna.

Keywords: Hermilo Borba Filho. Ariano Suassuna. Theatre in Pernambuco. Ideology.

Resumen: Este artículo propone una breve reflexión sobre las relaciones entre arte y política, con particular enfoque en un momento especialmente tieso y provocador en la historia del teatro en Pernambuco: la puesta en escena de la pieza A bomba da paz, escrita y dirigida por Hermilo Borba Filho, en 1962, producida por el Teatro Popular del Nordeste (TPN), un grupo teatral concebido por el propio Hermilo, en conjunto con el dramaturgo Ariano Suassuna.

Palabras-clave: Hermilo Borba Filho. Ariano Suassuna. Teatro en Pernambuco. Ideologia.

\footnotetext{
${ }^{1}$ Os conteúdos deste artigo, adaptados, foram aproveitados em partes do capítulo intitulado $O$ TPN de Hermilo e de Ariano, contido no livro "Teatro Popular do Nordeste: o palco e o mundo de Hermilo Borba Filho", de minha autoria, a ser lançado em breve pela Companhia Editora de Pernambuco

2 Doutor pelo Programa de Pós-Graduação em Letras da UFPE (PPGL/UFPE) e Professor do Departamento de Teoria da Arte e Expressão Artística da UFPE.
}

Este artigo está licenciado sob forma de uma licença Creative Commons Atribuição 4.0 Internacional, que permite uso irrestrito, distribuição e reprodução em qualquer meio, desde que a publicação original seja corretamente citada. https://creativecommons.org/licenses/by/4.0/deed.pt BR. 
Aos atores

Carrapateira, um curandeiro de Palmares, me contava quando eu era menino: "A humanidade é como um rio. Há aqueles que se localizam à margem esquerda e outros que se postam à margem direita. Vivem se guerreando, atirando pedras uns nos outros, jamais se reconciliarão. Os justos não se plantam nem dum lado nem do outro, descem a correnteza até atingirem o largo mar, com o horizonte infindo. Mas os pequenos ficam nas margens às voltas com as suas mesquinharias". A história de Carrapateira me veio à memória há poucos dias, a propósito da peça que começaremos a representar hoje. Pretendemos ser justos e apenas queremos chamar a atenção para os homens que estão nas duas margens, desviados. Isto não quer dizer que, apesar de tudo, não lhes tenhamos amor. E justamente porque os amamos ou porque, dentro de nossa condição humana, pretendemos amá-los, é que nos esforçamos para denunciar os seus erros, na agradável esperança de conquistálos. Se nada atingirmos, que importa? Nosso papel é esse, é essa a nossa função. A rigor não estamos atacando pessoas, mas mentalidades. Não existe nenhum ódio contra ninguém, mas lutamos no campo das ideias pela nossa sobrevivência. $\mathrm{O}$ que desejamos é muito melhor. É possível que tenhamos sido duros, aqui e ali, mas isso decorre do ardor do combate. Quero que vocês entendam isso, que acreditem em mim, porque é baseado nessa crença que poderão defender a obra que é tanto minha quanto de vocês, principalmente quando se sabe que a trabalhamos de comum acordo, desde as várias alterações no texto às discussões sobre os pontos controversos. Estamos todos engajados nesta conspiração cristã e justamente por isso, aliando-se a nossa condição de membros de uma comunidade que acredita em outros valores que não sejam os simplesmente humanos aos servidores do teatro, temos de ser ainda mais humildes diante de possíveis ataques. Não vamos aceitar provocações, mas vamos defender as nossas ideias e o nosso direito de opinião. Isto é outra coisa. Pela primeira vez praticamos realmente um teatro comprometido, mas a hora é tão grave que o homem tem que lutar com todas as armas de que dispõe e a nossa arma é o teatro, a caridade e o amor (Hermilo, em 25/4/1962, na ocasião da estreia de $A$ bomba da paz).

Aos atores

Muito obrigado pelo trabalho, pelo esforço, pela coragem de enfrentar um público quase sempre hostil: a verdade dói. Nem tudo correu como desejávamos, mas esta é uma das condições de nossa profissão. Nem por isso vamos deixar de pensar que 
estamos certos. O fato é que ajudamos um pouco a sacudir a consciência de cristãos e filisteus, e isto já é uma grande coisa. Fomos honestos e realizamos aquilo que achamos necessário. Eu estou satisfeito. Até mesmo com os erros que, cometidos de boa-fé, podem ajudar-nos na procura da perfeição (Hermilo, em 27/5/1962, ao término da temporada de $A$ bomba da paz). ${ }^{3}$

Estes dois textos, cartas ao elenco da peça $A$ bomba da paz, escrita e dirigida por Hermilo Borba Filho, de certo modo, sintetizam um tanto da complexidade artística e ideológica vivida pelo Teatro Popular do Nordeste (TPN) em seus primeiros anos de atividades. Fundado no segundo semestre de 1959, esse grupo teatral, que consolidou a modernidade na cena pernambucana, teve como principais mentores intelectuais Hermilo Borba Filho e Ariano Suassuna, fraternos amigos, companheiros de arte desde meados da década de 1940, quando estiveram juntos nos melhores anos do Teatro do Estudante de Pernambuco (TEP). Enquanto Hermilo permanece como diretor artístico durante toda a trajetória do grupo, que encerra suas atividades em 1975, Ariano tem atuação mais marcante como dramaturgo e como membro efetivo da diretoria do TPN, somente até 1963.

Nas poucas linhas que compõem as duas "tabelas"4 que abrem este artigo, encontram-se diversas e eloquentes senhas de aproximação com o pensamento e com o estado de espírito de Hermilo e dos seus companheiros de grupo, em suas crenças e em suas dúvidas, em suas conquistas e em seus recuos, durante os instigantes e tumultuados anos que precederam, no Recife, o golpe militar de 1964.

${ }^{3}$ Todos os documentos do TPN citados neste artigo fazem parte do acervo particular da atriz Leda Alves.

${ }^{4}$ Como se chamava esse tipo de comunicação entre diretores e atores. 
Vários aspectos precisam ser destacados no conteúdo desses dois documentos, devendo ser observadas não somente a complementaridade entre alguns dos elementos que estruturam a argumentação apresentada, mas também certa incompatibilidade entre outros deles, sintoma do momento de crise enfrentado pelo TPN. Considerem-se, pelo menos, os seguintes pontos articulados por Hermilo. Na primeira tabela: 1) a evocação e a valorização da convivência com a cultura popular, citando ensinamentos advindos de um "curandeiro de Palmares"; 2) a desaprovação de posicionamentos político-ideológicos radicais, à direita ou à esquerda, defendendo uma posição moderada, de centro; 3) o alinhamento com princípios cristãos, apreço por um ideal de justiça cristã, baseada no amor e na caridade; 4) a crença no teatro como instrumento de denúncia, tendo a cena o dever de espelhar os erros de cada sociedade ("teatro comprometido"); 5) a confiança na força pedagógica do teatro, presumidamente capaz de fazer as pessoas reconhecerem os seus erros e se corrigirem; 6) a percepção de que a arte teatral pode causar dor, pode incomodar, pode ser uma "arma”, suscetível, assim, a respostas agressivas, a "provocações", a "ataques"; 7) a visão um tanto idealizada do trabalho dos atores ("servidores do teatro"), tratando-o como uma missão que transcende valores "simplesmente humanos"; e 8) o reconhecimento do caráter processual e coletivo da criação teatral, cujos acertos e erros devem ser partilhados entre todos os envolvidos em cada trabalho. Na segunda tabela: 1) a expressão de agradecimento aos atores pela corajosa cumplicidade ao encarar reações hostis às ideias apresentadas na peça; 2) novamente, a crença no teatro como uma arte capaz de revelar "a verdade", reconhecendo que esse processo causa dor; 3) a confirmação do 
propósito de suscitar, por meio do teatro, uma oportunidade de reflexão (crescimento) para os espectadores, nesse caso, especialmente, para os “cristãos", mas também para os "filisteus"; 4) a disposição para refletir sobre o alcance, ou não, dos objetivos, reconhecendo que erros foram cometidos, embora "de boa fé", mas declarando-se, mesmo sem grande entusiasmo, "estar satisfeito" com o resultado obtido, uma vez que eventuais fracassos fazem parte da profissão dos artistas de teatro; e 5) a compreensão de que na arte, como na vida, não há perfeição, mas apenas uma "procura pela perfeição".

Contradições mais ou menos latentes desde a fundação do projeto afloram nesse momento com muita força, em um ambiente de agudo acirramento político-ideológico. Como ser popular e erudito a um só tempo? Como ser experimental sem se distanciar de um público escasso e reconhecidamente pouco afeito às vanguardas teatrais? Como ser cristão (católico) e praticar um teatro comprometido com as questões mundanas do aqui e do agora? Como evitar que a convicção religiosa dos líderes do grupo embace a sinceridade artística do projeto? Como harmonizar minimamente dentro de um mesmo coletivo, pessoas com diferentes credos, orientações e ideologias, a fim de prevenir evasões, querelas, dissidências e exclusões? Como pretender modificar o pensamento do espectador, "na esperança de conquistá-lo", sem abrir mão de motivações eminentemente artísticas para o fazer teatral? Como equacionar as motivações $\mathrm{e}$ as expectativas dos artistas, dos patrocinadores e dos espectadores, para tornar sustentável a atividade do grupo? Como combater tanto o teatro alienado quanto o teatro de instrumentalização política sem replicar, na prática, traços típicos dessas duas tendências? 
A bomba da paz buscou inspiração na poética da comédia antiga, da Grécia Clássica, que tem em Aristófanes a sua melhor expressão. Isso é dito, pelo próprio Hermilo, nas didascálias do intermezzo, proposto como "uma espécie de parábase" ao final do primeiro ato. Essa peça, uma corrosiva e desconcertante crítica à situação política no Recife dos primeiros anos da década de 1960, apresenta caricaturas de pessoas conhecidas na sociedade, rebaixando-as, representando-as em situações ridículas, grotescas, desmoralizantes, absurdas, de maneira semelhante ao que fazia o autor de As rãs, de As nuvens e, particularmente, de A paz, obra com a qual Hermilo dialoga, embora de modo muito livre, na criação de sua peça.

Talvez seja preciso, também, observar em $A$ bomba da paz uma visível influência do estilo empregado por Maquiavel em seu texto teatral mais importante, A mandrágora, peça traduzida e encenada por Hermilo meses antes no próprio TPN. Assim como Maquiavel fez renascer na Itália do século 16 certo ímpeto aristofanesco, Hermilo buscava, em bases modernas, reencontrar a força desconcertante desse modelo primordial, e talvez insuperável, de comédia política. E essa filiação à tradição clássica da dramaturgia ocidental, operada à luz da modernidade (experimental) do teatro, assenta muito bem, inicialmente, $A$ bomba da paz na proposta conceitual do TPN, expressa no Manifesto do grupo, divulgado em outubro de 1961, assinado por Hermilo e por Ariano.

Todavia, a realização desse espetáculo parece se justificar menos por sua possível consonância com o programa traçado para o TPN e mais pela urgente necessidade de um posicionamento político-ideológico mais contundente por parte de Hermilo, de Ariano e de seus companheiros de grupo. 
Nesse tempo, eles se encontravam no ápice de um forte embate com o Movimento de Cultura Popular (MCP). Hermilo e Ariano, que em maio de 1960 aparecem entre os fundadores desta organização, rapidamente afastam-se do projeto, declarando-se contrários a qualquer uso prioritariamente político do teatro, expressando repúdio ao que eles vão chamar de "arte alistada”. Estabelece-se, então, uma disputa entre o TPN e o MCP pela primazia no âmbito do teatro de vanguarda no Recife - levando-se em consideração que ser "vanguarda", nesse contexto, significava, em grande medida, ser "popular".

Os rivais do TPN recebem um enorme fortalecimento, em outubro de 1961, com a vinda do Teatro de Arena, de São Paulo, um dos grupos mais importantes da cena nacional, para realizar uma temporada popular na sede do MCP. Além de apresentarem o espetáculo Revolução na América do Sul, de Augusto Boal, oferecem oficinas de interpretação e de dramaturgia aos integrantes do setor teatral do MCP.

Tal ligação entre o Arena e o MCP deve ter sido dolorosa para Hermilo, visto que ele, como encenador, demonstrava grande admiração pelas realizações desses jovens artistas paulistas. No ano anterior, significativamente, Hermilo dirigira, para o Teatro de Arena do Recife, duas peças escritas por dois dos mais importantes nomes do Arena, de São Paulo: Marido magro, mulher chata, de Augusto Boal, e Eles não usam black-tie, de Gianfrancesco Guarnieri. E a sintonia entre o repertório desse coletivo teatral paulista e o do TPN vai se evidenciar em várias ocasiões: em 1960 o grupo de Hermilo apresenta A mandrágora, de Maquiavel, peça que o Arena vai levar à cena em 1962; em 1963, o conjunto paulista encena $O$ melhor juiz, o rei, de Lope de Vega, produzida pelo TPN, com a mesma adaptação dramatúrgica, em 1968; Tartufo, de 
Molière, montada pelo Arena em 1964, chega a ser ensaiada pelo conjunto recifense em 1968, mas o projeto é abandonado; dois meses antes de o TPN levar ao palco O Inspetor, de Gogol, talvez o seu mais bem-sucedido espetáculo, produção que inaugura a sede do grupo, o Teatro de Arena põe em cena a mesma peça, com o título de $O$ inspetor geral, dirigida por Boal, em maio de 1966. Além disso, o show A criação do mundo segundo Ary Toledo, concebido e produzido no seio do Teatro de Arena, fica em cartaz por quase dois meses na sede do TPN, no ano de 1967.

Um dos líderes do Arena, Nelson Xavier, entusiasmado com o projeto cultural implantado pelo prefeito Miguel Arraes, retorna ao Recife, no começo de 1962, a fim de trabalhar no MCP. Será dele a direção de Julgamento em Novo Sol, peça escrita por ele e por mais quatro autores, ligados ao Teatro de Arena: Augusto Boal, Hamilton Trevisan, Modesto Carone e Benedito Araújo. Esse espetáculo, talvez a mais importante produção teatral do MCP, estreia no dia 5 de maio de 1962, no grandioso Teatro de Santa Isabel. Nesse período, $A$ bomba da paz seguia em cartaz, no pequenino Teatro de Arena do Recife. Essa estreia acentua ainda mais o antagonismo entre o TPN e o conjunto teatral do MCP, que passara a se chamar Teatro de Cultura Popular (TCP).

Como o TCP posicionava-se marcadamente à esquerda, resta ao grupo de Hermilo a pecha de "direita"; muito embora, a rigor, o que se propunha era um posicionamento "ao centro", longe do alinhamento que, por exemplo, o Teatro de Amadores de Pernambuco (TAP), de Valdemar de Oliveira, naturalmente mantinha com as classes dominantes, mas igualmente distante das intenções revolucionárias, 
anticapitalistas, que animavam as ações teatrais do MCP, capitaneadas pelo ator e diretor Luiz Mendonça.

O tempo, porém, não demora a esclarecer que essa posição "de centro" do TPN pendia, efetivamente, para a esquerda. Após a tomada do poder pelos militares, atores do $\mathrm{MCP}$, severamente perseguidos pela repressão, como Evandro Campelo, Moema Cavalcanti e Joacir Castro, passam a integrar, de modo muito ativo, os elencos do TPN, participando de montagens corajosamente implicadas na luta contra o autoritarismo, contra a tortura, contra a falta de liberdade e de democracia. Outros artistas do MCP, como a cantora e compositora Teca Calazans, estarão próximos ao TPN, apresentando espetáculos na sede do grupo. Com pronta ajuda de Ariano Suassuna, Luiz Mendonça evita a prisão e consegue fugir para o Rio de Janeiro, com a esposa, Ilva Niño, ambos na clandestinidade (BACCARELLI, 1994). Entre 1966 e 1975, além de ter vários de seus integrantes fichados nos órgãos de monitoramento das forças repressivas, o TPN sofre diversas ameaças de grupos paramilitares de extrema direita, como o Comando de Caça aos Comunistas (CCC). A atriz Leda Alves, também fundadora do TPN, entrevistada por Regina Morganti, descreve as ações de resistência política praticadas no casarão no 1242 da Avenida Conde da Boa Vista, sede do grupo a partir de 1966:

Tudo quanto acontecia no país era denunciado ali, antes do espetáculo. "Foi preso fulano, desapareceu Sicrano..." A gente comunicava. O repertório era escolhido por Hermilo, todo com uma segunda intenção. Lutávamos contra a censura, contra o governo do Estado, contra a Ditadura. Sessenta e oito foi preparado dentro do TPN. Todo o trabalho de organização do velório do Padre Henrique [assassinado pelas forças repressoras em maio de1969], da passeata, do cortejo foi feito dentro do TPN. Ali os estudantes se reuniam. Tinham acabado com os sindicatos, os DCEs e os Conselhos Estudantis. Era no 
bar do TPN que eles se reuniam camufladamente e conspiravam (ALVES, 1994, p. 236).

Em outubro de 1961, matérias de jornal chegam a anunciar que Município de São Silvestre, de Aristóteles Soares, já estava sendo preparada como a próxima produção do TPN - peça que, de fato, só entra em cartaz após a temporada de $A$ bomba da paz. No Diario de Pernambuco do dia 11 de novembro de 1961, é noticiado que Ariano Suassuna estava escrevendo uma nova peça a ser estreada no começo do ano seguinte pelo TPN. A matéria destaca que "O título - acredita-se será uma surpresa e o tema é considerado extremamente atual”. Dias antes, um ofício do TPN, assinado por Leda Alves, solicita pauta ao Teatro de Santa Isabel, para a estreia de um suposto novo texto de Ariano, com o sugestivo título de $O$ inocente e os comunistas - peça que aparentemente ele não veio a escrever. Uma provocação? Talvez, sabendo-se que as pessoas responsáveis pela gestão municipal de cultura estavam, então, diretamente ligadas ao $\mathrm{MCP}$, onde atuavam artistas e intelectuais filiados ao Partido Comunista, ou pelo menos simpatizantes das ideias defendidas pelos comunistas. Por tudo isso, pode-se pensar $A$ bomba da paz como uma súbita reação aos avanços de setores da esquerda que, agora, se colocavam como francos antagonistas ao TPN. Embora não tenha sido escrita por Ariano Suassuna, mas sim por Hermilo, A bomba da paz foi, em grande medida, um projeto concebido por ambos, ou melhor, por vários dos integrantes do TPN, que se sentiam premidos a se posicionarem mais enfaticamente naquele contexto em que a esquerda ganhava cada vez mais evidência, sobretudo no campo da ação cultural. 
Na verdade, porém, o espetáculo atacava tanto a esquerda mais revolucionária quanto a direita mais reacionária, não poupando especialmente os falsos cristãos, ou os "cristãos acomodados", como dizia Hermilo, de variadas tonalidades ideológicas. Todavia, dadas as circunstâncias, $A$ bomba da paz parece ter favorecido, inopinadamente, as forças mais conservadoras, justamente os setores da sociedade que pouco depois, em abril de 1964, vão festejar a instalação do regime militar. Por tantas e tantas vezes, Hermilo procura, até o final de sua vida, se penitenciar desse erro. Em 1975, por exemplo, falando ao Serviço Nacional de Teatro, ele diz o seguinte: "Bem, esta peça era de circunstância, anticaridosa, não levava a lado nenhum politicamente, nasceu de uma raiva pessoal minha, que cometi o pecado de, além de escrevê-la, produzi-la" (BORBA FILHO, 2007, p. 215).

Ele se refere, nesse depoimento, ao seu desentendimento com Germano Coelho, presidente do MCP e então recém-empossado como diretor executivo do Departamento de Documentação e Cultura (DDC), espécie de secretaria da cultura da Prefeitura do Recife, responsável, entre outras coisas, pela administração dos teatros municipais. Hermilo, que desde a gestão do prefeito Pelópidas da Silveira ocupava um cargo remunerado no DDC, rompe com Germano Coelho ao discordar da forma, abrupta e não negociada, como fora removido de sua posição, após ter concebido todo um planejamento para o fomento à arte teatral no Recife, definindo, por solicitação do próprio Germano Coelho, os termos para o funcionamento de uma "Comissão de Teatro". A Hermilo, então, retirado do seu cargo original, é oferecida a presidência dessa recém-criada Comissão de Teatro, função aparentemente honrosa, mas, na prática, pouco prestigiosa, sem uma remuneração condizente com a 
responsabilidade a ser assumida. Para o lugar de Hermilo, no cargo que ocupava no DDC, Germano Coelho nomeia Paulo Freire, com o objetivo de assegurar a presença desse excepcional educador no MCP. Esses acontecimentos são detalhadamente relatados por Hermilo, embora transfigurados em literatura, no quinto capítulo de Deus no pasto, último volume da tetralogia de inspiração autobiográfica Um cavalheiro da segunda decadência, publicado no ano de 1972. Nessa passagem do romance, urdido no desconcertante espaço entre ficção e realidade, é mostrado que, em compensação pela perda do cargo, uma "importante" subvenção municipal é oferecida ao grupo de teatro dirigido pelo protagonista Hermilo, o "Teatro Popular", a fim de que o herói aceitasse permanecer à frente da "Comissão Municipal de Teatro". O personagem Hermilo nega a proposta, afirmando não confundir os recursos destinados ao seu grupo de teatro com os seus rendimentos pessoais; declarando ainda não estar interessado em cooperar com os novos planos propostos para a cultura da cidade, segundo ele, planos "muito confusos", uma esdrúxula "mistura de católicos e comunistas".

No livro MCP - História do Movimento de Cultura Popular, Germano Coelho apresenta, de modo sucinto, uma versão diferente para o episódio:

Findos os trabalhos, no Santa Isabel, no Parque e no Teatro do Arraial Velho, criamos, na Prefeitura do Recife, a "Comissão de Teatro" para movimentar o setor. Quando nomeei Hermilo Borba Filho presidente, rebentou a crise. Ele se demitiu pela imprensa. Deixou o MCP. Fez uma peça, levada pelo Teatro Popular do Nordeste - TPN. No Teatro de Arena, existente, então, na Avenida Conde da Boa Vista: “A Bomba da Paz". Eu e Norma fomos assistir o espetáculo. O prefeito do Recife era apresentado como uma pessoa rude e pouco educada. Eu, como presidente da "Sociedade de União de Católicos e 
Comunistas". Anita Paes Barreto como uma "catolicona vulgar" (COELHO, 2012, p.58).

A partir de então, o TPN enfrenta cada vez mais dificuldades para obter qualquer apoio, logístico ou financeiro, do setor que cuidava do teatro na administração municipal do então prefeito Miguel Arraes.

Nesse cenário, Hermilo e seu grupo conseguem o patrocínio do Governo do Estado de Pernambuco, por meio do Serviço Social Contra o Mocambo (SSCM), autarquia estadual criada em 1945 com o objetivo de reduzir o déficit habitacional no Recife. Mais especificamente, a parceria é celebrada com o Grupo de Trabalho de Promoção Social da SSCM, que pouco depois se transforma na Fundação de Promoção Social (FPS), entidade que de fato administra o patrocínio. No comando dessa fundação, encontrava-se Paulo Rodolfo de Rangel Moreira, amigo dos diretores do TPN, conhecedor do trabalho de Hermilo e de Ariano, desde os tempos do TEP, na Faculdade de Direito.

O termo de convênio para "atividades teatrais destinadas às classes populares", assinado em 16 de junho de 1961, deixa evidente o propósito de competir com as ações que o teatro do MCP vinha desempenhando havia mais de um ano. Comprometendo-se a estrear quatro peças por ano, o TPN receberia o montante de 1 milhão de cruzeiros, em uma parcela de 500 mil no ato da assinatura do contrato, mais cinco parcelas de 100 mil a cada 6o dias. Essa quantia, mais ou menos equivalente a 105 salários mínimos da época (determinado no valor de Cr\$ 9.600,oo pelo decreto no 49119, de 15 de outubro de 1960), não era suficiente para cobrir todos os custos envolvidos na produção de quatro espetáculos anuais, mas tornava minimamente viável a continuidade dos trabalhos, embora condicionada a um retorno favorável de vendas de ingressos. Mas o 
convênio garantia ainda uma renda mínima por apresentação. Caso o apurado na bilheteria em uma récita fosse inferior a 15 mil cruzeiros, a FPS complementaria a diferença entre esse valor e o total arrecadado.

Deve-se destacar, no conteúdo desse contrato, a ênfase dada, logo na primeira cláusula, ao compromisso de o TPN encenar "peças de autores nacionais e estrangeiros, de valor artístico e cultural" sendo-lhe reservado o "direito inviolável de independência artística, inclusive no que tange do [sic] repertório, diretores de espetáculos, cenógrafos, figurinistas, técnicos outros etc.". Com essa colocação, Hermilo e Ariano pretendiam evitar o risco de terem de repetir, embora em chave oposta, a mesma função instrumental, de arte politicamente aplicada, que eles tanto criticavam no teatro do MCP. A despeito dessa precaução, para Hermilo, o TPN terminara de certo modo incorrendo, com a encenação de $A$ bomba da paz, neste erro de usar a arte para fins alheios à própria arte.

Outra informação que merece destaque no contrato com a FPS é a promessa de que seria construído, "na Ilha de João de Barros, à margem da Avenida Beira Canal", em terreno pertencente à SSCM, um "teatro de emergência" para abrigar o TPN. Isso, porém, jamais aconteceu, levando Hermilo e seus companheiros a apresentarem os dois últimos espetáculos dessa primeira fase do grupo (A bomba da paz e Município de São Silvestre) no Teatro de Arena do Recife, arcando com a locação do espaço, o que certamente contribuiu para a suspensão dos trabalhos ao final de 1962 por falta de viabilidade financeira. O arquiteto Ubirajara Galvão, ator, cenógrafo e figurinista do TPN, chega a entregar à FPS o projeto arquitetônico para a construção desse teatro que abrigaria o grupo de Hermilo e de Ariano. Mas as obras jamais foram iniciadas. 
A assinatura do contrato de patrocínio com a FPS não obteve, porém, a concordância unânime da diretoria do TPN. O dramaturgo Aldomar Conrado, ligado à União da Juventude Comunista, repudia de modo enfático essa aproximação com um governo que se opunha abertamente às ações progressistas que o então prefeito Miguel Arraes começava a desenvolver no Recife. Em um momento de incompreensão, ou mesmo de intolerância, em que as divergências no âmbito político foram magnificadas pelas diferenças de ordem pessoal, Aldomar Conrado é afastado do TPN. No mesmo ano, ele se muda para o Rio de Janeiro e ingressa no Centro Popular de Cultura (CPC), da União Nacional dos Estudantes (UNE), experiência em grande medida irmanada, em seus objetivos, ao Movimento de Cultura Popular.

Para o Governo de Pernambuco, como visibilidade política, o que certamente mais interessava eram as apresentações de peças nos bairros, sobretudo nos Centros Educativos Operários. Tal ação, no entanto, implicava graves perdas na qualidade artística das encenações, devido à falta de condições técnicas nesses espaços. Hermilo não demora a perceber que o TPN não estava sendo justo, nem consigo mesmo nem com o povo, ao apresentar versões esteticamente diminuídas das montagens. No entanto, a princípio, ele não deixa de reconhecer o valor formativo daquelas experiências. Em tabela escrita quase ao final da temporada de $O$ processo do diabo, primeira produção feita com o patrocínio da FPS, Hermilo diz o seguinte:

Encerramos hoje a fase inicial de experiência nos Centros Operários. Simplesmente em relação ao prazer pessoal de cada um, como intérprete, os tropeços foram sem conta, dando, por vezes, a impressão de que estávamos trabalhando inutilmente. Mas se atentarmos para o que significaram essas 
representações como calor humano, capacidade de desprendimento e contato com camadas pobres de nossa sociedade, vamos verificar que há um saldo a nosso favor. Quando nada um saldo de esperança. O povo, em geral, tem direito à arte, mesmo contra a sua vontade. Se estivermos bem certos disso ficaremos mais animados para próximos espetáculos, cada vez mais conscientes de nossa função como artistas e como irmãos de todos. Estamos aprendendo muita coisa, não tenham dúvidas, dentre as quais a menor não será a humildade. E nada mais importante do que aprender. Todos com todos. Mais uma vez muito obrigado e um FELIZ NATAL (Hermilo, 18/12/1961).

Com a continuidade dos trabalhos, em meio a divergentes opiniões dos componentes do TPN sobre a questão, o que prevalece, porém, é a constatação de que apresentar uma obra sem a sua completude artística era, de certa maneira, um desrespeito a essas plateias, uma forma indireta de julgá-las menos exigentes, inferiores. Hermilo expressará esse entendimento em várias entrevistas e reportagens.

Essa rejeição às apresentações nos Centros Educativos Operários, em paralelo à incapacidade de a FPS cumprir a promessa de construir uma sede para o TPN, e também à alegada insuficiência dos recursos acordados para as montagens dos espetáculos tornam inviável a continuidade da parceria, que é encerrada em janeiro de 1963. Não se pode esquecer, também, que a eleição de Miguel Arraes para governador do estado, em outubro de 1962, tornava improvável a permanência do convênio entre o TPN e a FPS.

Nesse período, a atriz Leda Alves, muito engajada nas ações da Igreja Católica, começa a trabalhar no Movimento de Educação de Base (MEB), projeto educacional fundado em março de 1961 pela Conferência Nacional dos Bispos do Brasil (CNBB). Em entrevista a Vera Morganti, Leda Alves fala sobre o convênio estabelecido entre o MEB e o TPN, vigente entre março e dezembro de 1963, lembrando que "Hermilo 
escrevia e dirigia os atores para gravar essas aulas, como rádio-teatro" (ALVES, 1994, p.229). Curiosamente, no ápice da disputa entre o TPN e o MCP, Hermilo e seus comandados aproximam-se do MEB, um projeto que guardava reconhecíveis semelhanças com alguns dos principais objetivos do MCP, sendo as duas iniciativas fortemente combatidas pelas forças que assumem o poder em abril de 1964.

O mais evidente ponto de interseção entre o projeto comandado por Germano Coelho e o TPN era certamente a aproximação que ambos tinham com a Igreja Católica. Oportuno notar, também, que o TPN, como um todo, não estava distante das ações desenvolvidas por Paulo Freire: Gastão de Holanda, um dos fundadores do grupo, fez parte da equipe do Serviço de Extensão Cultural (SEC), da Universidade do Recife, coordenando a Rádio Universidade, cuja missão era a "democratização da cultura" (VERAS, 2016, p. 28). Havia décadas, afinal, que Hermilo, Ariano, Gastão e seus colegas do TEP e, agora, do TPN trabalhavam em prol da democratização do acesso à cultura e à arte; mais que isso, defendiam também a valorização da cultura e da arte praticadas pelas camadas socialmente desfavorecidas. Luiz Mendonça, líder do setor de teatro do MCP, sempre reconheceu as ações dos criadores do TEP como uma primordial inspiração para o seu trabalho (MENDONÇA, 1968).

Em contexto tão repleto de adversidades, com tamanha dificuldade para que um conjunto teatral se mantivesse operante, pode-se dividir essa primeira fase do TPN em dois momentos: antes e depois do patrocínio concedido pelo Governo de Pernambuco, via Fundação da Promoção Social. Sem esse apoio, decerto o conjunto liderado por Hermilo e por Ariano teria encerrado suas atividades muito 
precocemente, por absoluta falta de condições de trabalho, antes mesmo de produzir o seu espetáculo mais polêmico: A bomba da paz.

Essa peça suscita enorme repercussão na imprensa local, com diversas resenhas críticas, quase todas apontando a predominância do interesse político sobre o valor artístico propriamente dito da obra. A resposta do público, em termos de bilheteria, não é má. São dadas 45 apresentações durante a temporada. Mas, como o Teatro de Arena do Recife tinha apenas 94 lugares, menos de $10 \%$ da capacidade do Teatro do Parque, onde o grupo apresentara os trabalhos anteriores, pode-se afirmar que não foi uma das mais vistas produções do TPN.

A montagem, porém, também suscitou, ou catalisou, desavenças entre participantes do TPN. Joel Pontes, por exemplo, velho companheiro de Ariano e de Hermilo, ex-integrante do Teatro do Estudante de Pernambuco (TEP), faz fortes críticas ao espetáculo em sua coluna jornalística, afirmando que o TPN tomara um rumo incompatível com o espírito do TEP, grupo do qual anunciava ser uma continuidade. Ariano Suassuna, para quem a coerência foi sempre um valor inconteste, responde com veemência por meio de um longo artigo, intitulado "Esquerda, Direita e Teatro", publicado no Jornal do Commercio, em 10 de junho de 1962:

O crítico Joel Pontes afirmou que o Teatro Popular do Nordeste não pode ser considerado continuador do Teatro do Estudante de Pernambuco. Acha ele que o TEP era um grupo de esquerda e que o Teatro de Cultura Popular - o teatro político do MCP continua melhor a linha do TEP - inclusive pelo amadorismo dos jovens que o integram.

Não é verdade que o TEP fosse um grupo de esquerda; como não é verdade que o TPN seja um grupo de direita. E já que o ilustre crítico está agora tão cioso da linha e dos direitos do TEP - que abandonou no meio, deixando-nos sós, na pior das crises - devia ter protestado em sua coluna contra o programa 
de 'Julgamento em Novo Sol': ali se afirma que o primeiro teatro ao ar livre, de caráter ambulante, que se fez no Recife foi o circo do MCP. Isso não tem grande importância, é dito por demagogia; mas Joel Pontes sabe, melhor do que eu, que o primeiro teatro desse tipo foi, no Recife, A Barraca, do Teatro do Estudante, estreada no Treze de Maio, em 1948. [...]

Outra coisa que agradecerei é que os 'gorilas' da extremadireita e os mais privilegiados do que eu não me confundam com eles somente porque me defino contra o comunismo. [...] Tenho à extrema-direita a mesma aversão que tenho à extrema-esquerda. Infelizmente os comunistas, com sua filosofia primária, seu espírito de rebanho, sua hipocrisia, sua brutalidade policial organizada atrapalham a nossa luta.

Nunca vi um espetáculo tão injustiçado, no Recife, como 'A Bomba da Paz'. Gente que se amoitou sobre a política do MCP, no teatro, apareceu, de repente, travestida de vestal, a defender a pureza do teatro.

A peça é inteligente, faz pensar, é sincera, é uma advertência e uma denúncia. É claro que não agrada aos 'veados cor-de-rosa' - como as peças da 'esquerda amestrada' me parecem, todas, umas porcarias. Toda peça política só é apreciada pelos que pensam do mesmo modo. Mas uma só carta de Hermilo Borba Filho tem mais teatro do que todas as peças escritas e dirigidas por esses rapazes bem alimentados que nos têm aparecido por aqui, aos magotes, medindo nossas calorias, salvando e planejando nossa pobreza (SUASSUNA, 1962, sem paginação).

Assim, como se pode depreender da repercussão da temporada de A bomba da paz, as circunstâncias parecem ter contribuído fortemente para que o TPN, grupo conceitualmente alicerçado em diretrizes poéticas e ideológicas muito eloquentes, expressas por meio de um robusto manifesto em outubro de 1961, terminasse por tensionar ao limite um dos eixos centrais de seus valores fundantes: a prática de um teatro isento de motivações partidárias.

Após essa montagem, o contrato com a Fundação de Promoção Social ainda garantiria a encenação de mais uma peça: Município de São Silvestre, de Aristóteles Soares. O texto, vencedor de um concurso de dramaturgia cuja premiação previa a montagem da obra pelo TPN, subiu 
ao palco com direção artística do ator José Pimentel, primeiro no grupo a assumir a missão de substituir Hermilo na função de encenador. Recebido sem grande entusiasmo pela crítica, o espetáculo foi o último trabalho do TPN a percorrer os Centros Educativos Operários, encerrando a parceria com a Fundação de Promoção Social.

Sem recursos financeiros, e ferido pelas divergências políticoideológicas, enfrentadas dentro e fora do grupo, o TPN decide que somente retornaria às atividades quando conseguisse conquistar um lugar próprio para abrigar as suas produções, algo que somente acontece em 1966, quando tem início uma fase ainda mais instigante e prolífica da trajetória artística do grupo liderado por Hermilo.

\section{Referências}

ALVES, L. Depoimento. In MORGANTI, Vera (Org.). Confissões do amor e da arte. Porto Alegre: Mercado Aberto, 1994.

BACCARELli, M. (Org.). O teatro em Pernambuco: trocando a máscara. Recife: Fundarpe, 1994.

BORBA FILHO, H. Depoimento. In CORREYA, J.; ALVES, L. (Orgs.) A palavra de Hermilo. Recife: CEPE, 2007.

. Deus no pasto / Quarto volume da tetralogia. Um cavalheiro da segunda decadência. Rio de Janeiro: Civilização Brasileira, 1972.

COELHO, G. MCP - História do Movimento de Cultura Popular. Recife: Edição do Autor, 2012.

MENDOÇA, L. Teatro é festa para o povo. In: REVISTA Civilização Brasileira Caderno especial n. 2: Teatro e realidade brasileira, julho de 1968. Rio de Janeiro: Civilização brasileira, [199-].

SUASSUNA, A. Esquerda, Direita e Teatro. Jornal do Commercio. 10 jun. 1962. 
VERAS, D. B. Sociabilidades letradas no Recife: a revista Estudos Universitários (1962-1964). Recife: Editora Universitária da UFPE, 2012.

Recebido em 06/10/2017.

Aprovado em 09/10/2017. 